\title{
Historia y anacronía: \\ El Diario de noticias sobresalientes de Lima (1700-1711) y la muerte de un rey
}

History and Anachrony: The Diario de noticias sobresalientes de Lima (1700-1711) and the Death of a King

\author{
Esperanza López Parada \\ Universidad Complutense de Madrid \\ https://orcid.org/0000-0002-4240-8034
}

CESXVIII, núm. 31 (2021), págs. 13-36

DOI: https://doi.org/10.17811/cesxviii.31.2021.13-36

ISSN: 1131-9879

ISSNe: 2697-0643
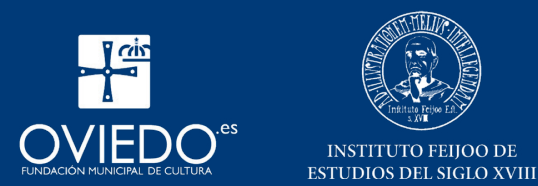
El Diario de noticias sobresalientes en Lima y noticias de Europa, primera de las publicaciones periódicas peruanas que se conoce, se abre con la conflictiva muerte del rey Carlos II o, más bien, con los avatares de la llegada de su noticia; porque, de hecho, esta llega a Nueva España casi cuatro meses después de producirse la defunción y acompañada de la nueva de la jura de su sucesor, lo que asegura la continuidad de cara a las colonias, mientras en Europa los países implicados se hundían en una larga guerra sucesoria. Pero en Perú la noticia, mucho más tardía puesto que se confirma en mayo, se acompaña en cambio de una carta de enero del nuevo monarca, avisando de ataques holandeses e ingleses a las Indias, carta de aviso muy anterior al conocimiento de su proclamación, lo que solo añade más incertidumbre y una especie de caos cronológico con la que se las tendrá que haber el discurso. La historia debe siempre ser reescrita porque ella misma cambia, según Kosseleck, pero ¿qué tanto de cambio obedece a la propia redacción?, ¿cuánto de modificación introduce el hecho de enterarse tarde? A partir de esa condición demorada de la noticia americana, el presente artículo se propone estudiar los desarreglos temporales, las relegaciones y desórdenes de sentido en el texto periférico virreinal y en la recepción en concreto de la noticia de la muerte del rey, así como los mecanismos narrativos con que el Diario de noticias sobresalientes pretende solventarlos o, más humildemente, sobrellevarlos.

Palabras clave

Diario de noticias, anacronía, historia, muerte de un rey, problemas sucesorios

\section{Abstract}

The Diario de noticias sobresalientes en Lima y noticias de Europa, the first Peruvian publication known, opens with the conflictive death of King Carlos II or, rather, with the incidents of the arrival of his news, since, in fact, it arrives in New Spain almost four months after the death and accompanied by the news of the oath of his successor, which enssures the continuity of the colonies. Meanwhile in Europe the countries involved were sinking in a long succession war. But in Peru the news, which reached much later having been confirmed in May, was instead accompanied by a January letter from the new monarch warning of Dutch attacks in the Indies; a letter of warning well before his proclamation was known, which only added further uncertainty and a kind of chronological chaos to the discourse. History must always be rewritten because it changes itself, according to Kosseleck. But, how much of the change is due to the writing itself? And how much of the change is brought about by the fact of finding out late? From this delayed condition of the American news, the present article intends to study the temporal disorders, the relegations and disorders of meaning in the viceroyalty's peripheral text, and in particular in the reception of the news of the king's death, as well as the narrative mechanisms with which the Diario de noticias sobresalientes tries to solve them or, more humbly, to overcome them.

\section{KEY WORDS}

News journal, anachronism, history, death of a king, inheritance problems

Recibido: 31/12/2020. Aceptado: 18/3/2021. 
La versión fílmica de Zama, la novela colonial de Antonio di Benedetto que llevara al cine la directora argentina Lucrecia Martel, muestra una escena de salón durante la cual la dama Luciana Piñares de Dueña, que recibe en su casa, comenta el detalle de que las tazas en que están tomando el café habían llegado de España envueltas en diarios y papeles con fechas más recientes y noticias más frescas que aquellas recibidas en la corte por medios oficiales.

Resulta muy interesante en la escena, que pertenece solo al guion de la película, esta asunción doble de una conciencia: por un lado, conciencia de la separación que implica la condición subordinada a un centro del imperio donde lo que ocurre, ocurre siempre antes. Por otro, la percepción comprobada de un desfase cuando se cuenta algo que, informado oficialmente, viene lastrado con una tardanza respecto a otras vías de conocimiento azarosas, en principio menos fiables y, por contra, más exactas, insistiendo de cualquier forma en que ambas fuentes - la oficial, la azarosa - actúan con retardo respecto al foco de información.

El 1 de noviembre de 1700 muere sin hijos el hechizado Carlos II, tras pronunciar la frase, nada estoica, «Me duele todo». A partir de ese momento se desencadena una grave situación dinástica, profetizada y temida desde el segundo y frustrante matrimonio del rey con María Ana de Neoburgo, y claramente manifiesta a partir de la entronización de Felipe V, su sobrino borbón, con la declaración de guerra entre franceses y españoles contra holandeses e ingleses, partidarios del candidato de la casa de los Austria.

El dato del deceso, sin embargo, no llega a Nueva España hasta el primer domingo de marzo de 1701, en que «entró correo de la Veracruz con nueva de aviso, (...) empabezado de negro, y con gallardetes y banderas del mismo color, disparando cada media hora una pieza, en demostración de la muerte del rey nuestro señor Carlos II, que descanse en paz», de acuerdo con el Diario que para el Virreinato recogiera Antonio de Robles dos años más tarde ${ }^{1}$.

En cambio, según el Diario de noticias sobresalientes en Lima y noticias de Europa que, anónimo e impreso por Joseph de Contreras, cubre el periodo

1 Antonio De Robles, Diario de sucesos notables (...) y comprende los años de 1665 a 1703, México, Imprenta de Juan R. Navarro, 1853, pág. 603. 
comprendido entre 1700 y 1711, en la capital del virreinato del Perú la noticia se conoce en mayo, al anochecer del día 6, cuando el sargento mayor don Manuel Fernández Velarde, de la orden de Santiago y corregidor de Pacajes, confirme el aviso de «haber muerto el Rey nuestro señor (que está en gloria)», aunque antes se hubieran recibido cartas particulares de Panamá y prensa de Paita dando la nueva, que se publicita por la ciudad solo entonces, a partir de la tardía confirmación oficial y a golpe de la campana grande de su catedral, «a que siguieron todas las demás iglesias, durando sin cesar toda la noche en el doble» ${ }^{2}$. De inmediato se cerraron los tribunales y salas de audiencia, ministros y jueces se retiraron a sus casas y la milicia «dobló sus banderas, destempló sus cajas y clarines y abatió sus armas boca en tierra», mientras el presidio del Callao, durante dos días, del 9 al 11 de mayo, disparaba su artillería cada cuarto de hora ${ }^{3}$.

La mañana del 13, en una corte ceremoniosa y apesadumbrada, el virrey recibía el pésame de la Real Audiencia, el Tribunal Mayor de Cuentas, el Tribunal de Cruzada, los Cabildos de iglesia y ciudad, el claustro de la Real Universidad, el Real Colegio de San Felipe, el Colegio Real de San Martín, el seminario de Santo Toribio, junto a prelados, jueces y nobleza:

[...] en muy crecido concurso, enlutada con faldones y capas largas, los jefes militares de primera plana, de lutos y corbatas de tafetán negro, fajadas de bayeta sus insignias; por la tarde el señor Arzobispo, después del Tribunal de la Inquisición y demás personas de cuenta, a quienes su Excelencia, estimándoles su amor y lealtad para con la memoria de nuestro rey y señor, les aumentó la ternura y avivó el dolor con la viva expresión de su sentimiento ${ }^{4}$.

2 Diario de noticias sobresalientes en Lima y noticias de Europa (1700-1711), vol. 1 (1700-1705), edición y estudio de Paul Firbas y José A. Rodríguez Garrido, New York, IDEA/IGAS, 2017, pág. 95.

3 «6 [mayo]. Al anochecer llegó el aviso de España, que trujo el sargento mayor don Manuel Fernández Velarde, del Orden de Santiago, corregidor de Pacajes, y se confirmó la noticia triste de haber muerto el Rey nuestro señor (que está en gloria)».

«7 [mayo]. Se dio a la ciudad la noticia pública, comenzando a las 12 del día la iglesia catedral a clamorear con 100 golpes de su campana grande, a que siguieron todas las demás iglesias, durando sin cesar toda la tarde hasta entrada la noche en el doble, que se va continuando todos los días hasta que se hagan las honras. Cerráronse los tribunales y salas de audiencia, retirándose los ministros y jueces al justo duelo y dolor en sus casas. La milicia dobló sus banderas, destempló sus cajas y clarines, y abatió sus armas boca en tierra; el presidio del Callao, desde el día 9 hasta 11, disparó su artillería a cada cuarto de hora su pieza, comenzando y cerrando este su funesto estruendo y clamor con salvas de toda su artillería. Echose bando poniendo precio a las bayetas a 7 pesos las teñidas en Sevilla y las teñidas en Lima a 6, con pena al que le quebrantase», Diario de noticias sobresalientes en Lima ..., pág. 95.

4 «13 [mayo]. Este día recibió su Excelencia los pésames de los tribunales de esta ciudad; Real Audiencia, el Tribunal Mayor de Cuentas, el Tribunal de Cruzada, el venerable deán y Cabildo de esta santa iglesia, el Cabildo de esta ciudad con los jueces oficiales reales; la Real Universidad en forma de claustro, el 
Sin embargo, y pese a la gravedad de este suceso, las noticias europeas que el Diario consigna, llegadas a Perú de manera oficial entre el 8 de abril y el 18 de mayo de 1701, atañen a sucesos acaecidos en otoño del año anterior: la muerte de Su Santidad en Roma y la constitución del cónclave para la elección del papa; el nombramiento por parte de Su Majestad «(que está en gloria)» del gobernador del Consejo de hacienda; el rescate por los trinitarios de esclavos franceses en Trípoli, Argel y Túnez; el abandono de los escoceses de la colonia del Darién, por el perjuicio del clima y la salud, «que los que salieron con vida perecieron en el viaje a Jamaica»; o la centella que en Tarragona a medianoche cayó en el almagacén de la pólvora (...) y que «volando desde los cimientos (...) hizo mucho estrago en las iglesias, conventos y demás edificios fuertes» ${ }^{5}$.

Situadas todas estas «noticias generales de Europa» en la sola fecha que el pasaje ofrece de ellos — 27 de septiembre en que fallece el papa-, parecen flotar en la intemporalidad indecisa del retardo con que se cuentan, de ese pasado detenido cuya lentitud en darse a conocer los desdibuja.

$\mathrm{Ni}$ una sola mención entonces para Lima, del infausto hecho que conmovía en ese momento la cabeza del imperio, hecho cuya confirmación alcanza a la villa con considerable retraso: aunque, como veremos, se conocía antes, no es hasta el 17 de enero de 1702 que se proclame oficialmente la defunción de Carlos II:

Llegaron esta noche de Panamá dos paquetes de cartas re[g]ulados: por el Rey, al Virrey, presidente y oidores de la Real Audiencia de Lima; causó gran cuidado lo inopinado de su llegada, y comenzó la curiosidad a discurrir, como suele, muchas novedades. Convocó Su Excelencia a los señores ministros, y abiertos se hallaron ser pliegos triplicados y cuadruplicados de la muerte de nuestro rey y señor don Carlos II (que está en gloria), y muchas cartas a las ciudades y villas del reino para que se levanten pendones por el Rey nuestro señor don Felipe $\mathrm{V}^{6}$.

De hecho, el nombramiento del sucesor en noviembre de 1700 ya se había conocido y celebrado en Perú en septiembre de 1701, anticipándose de este modo a la llegada efectiva de los cajones y los despachos de España, que habían quedado retenidos en Portobelo desde el 14 de junio, como por otra parte participa y denuncia un gentilhombre en carta al virrey del 18 de ese mes:

Real Colegio de San Felipe, el Colegio Real de San Martin, el Colegio Seminario de Santo Toribio, el Tribunal del Consulado, los prelados de todas las religiones», Diario de noticias sobresalientes en Lima..., pág. 95.

Diario de noticias sobresalientes en Lima ..., pág. 97.

6 Diario de noticias sobresalientes en Lima ..., págs. 126-127, subrayado mío. 
A nueve de este mes de septiembre [de 1701] recibió el excelentísimo señor conde de la Monclova, virrey de estos reinos, carta del señor don Jerónimo de Córdova, oidor más antiguo de la Real Audiencia de Panamá, su fecha de junio de este año, en que le avisa cómo habiendo llegado a Portobelo el día 14 de junio el gentilhombre que trae los cajones del aviso de España para este Reino, en un paquete que se abrió en el Real Acuerdo, se hallaron unos pliegos para su Excelencia (y se los remite inclusos en su carta); y que, habiendo ocasión próxima de embarcación, ha dispuesto salga luego, dejando otra que se quedaba aviando para que la siga con el gentilhombre y los cajones ${ }^{7}$.

Así pues y en una especie de sinopsis agotadora, la muerte de un rey sin hijos se conoce y confirma oficialmente después de la provisión, también oficial, de su sucesor y siguiendo un tempo de dilaciones en el que es parte alícuota de la cuestión la propia demora:

1 de noviembre de 1700: muerte del Rey Carlos II

27 de noviembre de 1700: proclamación del rey Felipe V

8 de abril y el 18 de mayo de 1701: se reciben en Lima noticias europeas concernientes al otoño del año anterior pero nada sobre el deceso de Carlos II

14 de junio de 1701: llegada a Portobelo de los cajones oficiales con la noticia de la muerte y la proclamación del heredero

18 de junio de 1701: carta del oidor de Panamá avisando de que dichos cajones quedan retenidos

Septiembre de 1701: celebración de la coronación del rey Felipe V

Septiembre de 1701: llegada a Lima del aviso de Panamá de que no llegan los avisos oficiales.

17 de enero de 1702: llegada a Lima de los paquetes retenidos y apertura de los pliegos triplicados con la noticia oficial de la muerte del Habsburgo y la coronación del rey Borbón.

El ramillete de fechas retrasadas que rodea la plena información de asunto tan crucial subraya, por un lado, esta realidad de la recepción americana de noticias constituida en una nueva más, dentro de un ejercicio metacronológico por el que recibir o no recibir se convierte en asunto noticiable en sí mismo.

Por otro lado, la desilusión imaginable que grava la apertura de aquellos pliegos oficiales tan desfasados y caducos — cuando «lo inopinado» de su aparición incitaba la curiosidad y sospecha de novedades - constata de nuevo las

${ }^{7} \quad$ Diario de noticias sobresalientes en Lima ..., pág.109. 
diferentes velocidades que adopta toda noticia en las Indias, así como la temporalidad relegada desde la que se obtiene, esa conciencia del retraso con que se conoce algo, como si el juego continuo de la postergación y la demora se conformaran en tanto su condición permanente.

\section{El Diario de Noticias Sobresalientes en la Lima de 1700}

Nuestra principal fuente para el estudio de este tiempo anacrónico de la colonia, en medio de la historicidad progresiva y lineal que la modernidad ilustrada impone como cronología por esencia del progreso, este Diario de Noticias que aparece en la ciudad de los Reyes en 1700 resulta ser la primera relación

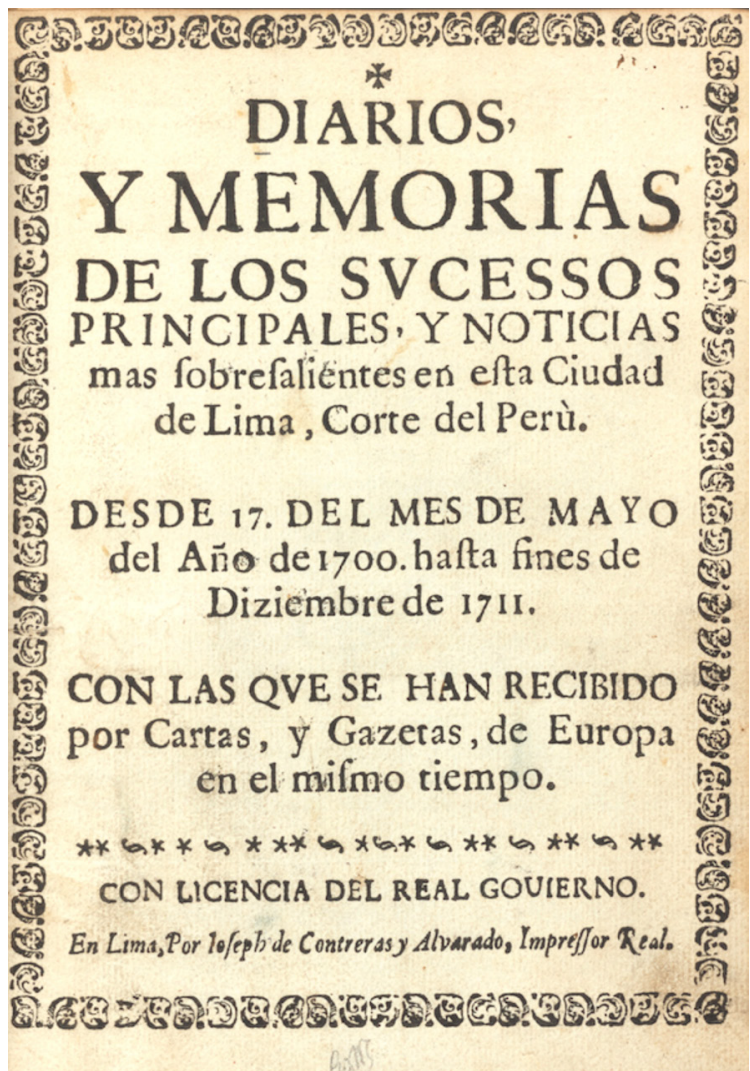

Fig.1: Diario de noticias sobresalientes de Lima y de Europa (1700-

1711)..., Lima, Por Joseph de Contreras y Alvarado, Impresor Real,

[1700-1712] (The New York Public Library, Digital Collections) 
diarística que conozcamos en el continente americano con la voluntad de compendio y de continuidad que es propio de este tipo de publicaciones.

Hasta él, lo que existía en el Perú y en todo el imperio eran boletines ocasionales, publicados solo cuando un acontecimiento concreto así lo demandaba, que seguían modelos peninsulares y se encontraban destinados a un receptor minoritario con el que entablar un vínculo jerárquico, unívoco, normativo y vertical $^{8}$.

En Europa, las impresiones periódicas tienen su arranque en la segunda mitad del siglo XVII pero el término diario no se aplica todavía a estas, ya que se percibe como más propio de escrituras íntimas y singulares, lo que hace que su aparición al frente del texto que nos ocupa pueda deberse a su distribución de noticias por días:

En principio, los diarios mantienen una estrecha relación temporal con los sucesos y suponen una forma de escritura casi inmediata [...]. En todo caso, el nombre diario no estaba consagrado para la publicación impresa de noticias periódicas. [...] Creemos que el uso de la palabra diario en nuestro volumen apunta en dos sentidos: el más explícito tiene que ver con la disposición y el orden por días de las noticias dentro de un documento, que podía abarcar un arco temporal de hasta dos meses; y el otro, conectado con las relaciones de sucesos, es decir, con una forma de escritura muchos más narrativa que informativa9

Promovido por el Conde de la Monclova, cuya presencia protagoniza la primera mitad del Diario, este podría identificarse con el que menciona la $G a-$ ceta de México ${ }^{10}$ en enero de 1722, que lo señala como el primero en producirse en el Nuevo Mundo con una periodicidad mensual. Si bien de forma un poco irregular, pero al menos cada dos meses, con una abundancia de 5 a 8 números anuales desde 1700 a 1711 , se van recogiendo en la publicación no solo los acontecimientos locales sino también las nuevas europeas, en cuya redacción debieron participar intelectuales de la elite criolla del renombre de Peralta o Bermúdez de la Torre, mientras que en la recopilación y reproducción de los segundos trabajarían los impresores de modo directo.

8 María Mendoza Michilot, Inicios del periodismo en el Perú: Relaciones y noticiarios, Lima, Universidad de Lima, Fondo de Desarrollo Editorial, 1997, pág. 19.

9 Paul Firbas y José Antonio Rodríguez Garrido (eds.), «El Diario de noticias sobresalientes en Lima y las Noticias de Europa (1700-1711) en su contexto histórico y editorial», en Diario de noticias sobresalientes en Lima..., pág. 31.

10 Gaceta de México: Castorena y Ursúa (1722). Sahagún de Arévalo (1728-1742), vol. 1, intr. de Francisco González de Cossío, México, Secretaría de Educación Pública, 1949. 
En ese sentido, no sabemos bien qué tanto de autoría le correspondió a Joseph de Contreras, el importantísimo editor por cuyo saneado negocio pasaba lo mejor destinado a la prensa de lo producido en el Perú en su tiempo ${ }^{11}$.

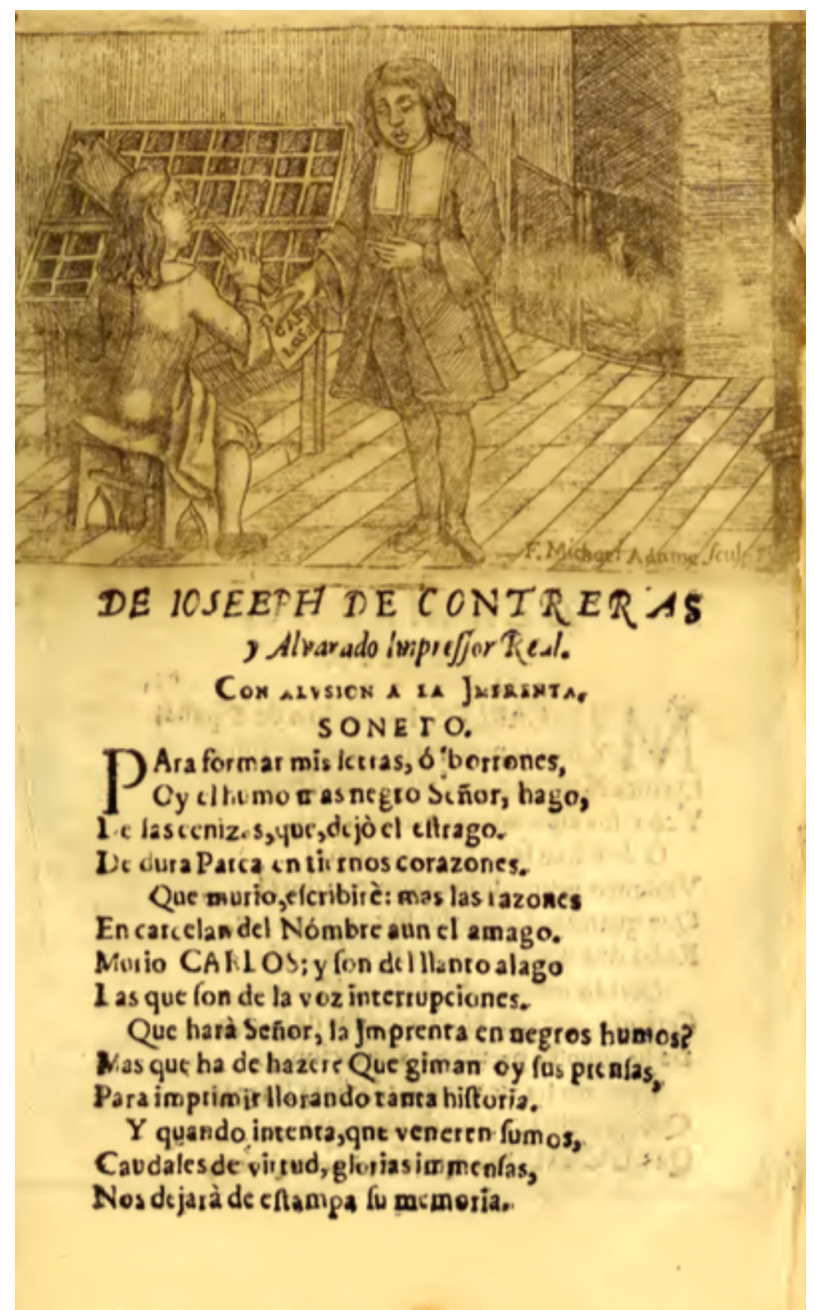

Fig.2: «Joseph de Contreras en su taller», José de Buendía,

Parentación real al soberano nombre e inmortal memoria del

Católico Rey de las Españas... (The John Carter Brown Library)

11 En el análisis del notable papel jugado por este impresor en el Virreinato, es imprescindible el reciente estudio de Pedro Guibovich Pérez, Imprimir en Lima durante la colonia. Historia y documentos, 15841750, Madrid, Iberoamericana-Vervuert, 2019. 
Sin duda alguna, Contreras era, además de empresario, un hombre culto, documentado, autor él mismo de poesía. Hasta 1691 había trabajado por cuenta ajena, pero, a partir de esa fecha adquiere en remate la imprenta de Manuel de los Olivos y, al igual que su padre, obtiene el privilegio de ser nombrado Impresor real, nombramiento cuya celebración se detalla en algún pasaje del Diario.

Una cuestión importante de este último se desprende de las condiciones materiales de su producción. Al no presentar tipografía ni impresión claras, dinámicas y atractivas, Guibovich ${ }^{12}$ sospecha que se tiraba «en una prensa de segunda mano, en no muy buenas condiciones, que había estado operativa durante largo tiempo», como por otra parte refiere el inventario de bienes de Contreras y Alvarado de 1715:

En él se registró una imprenta muy gastada por haver estado cerviendo más de beinte años. Los descuidos en la impresión, visibles en las erratas y las omisiones textuales, pudieron haber sido también producto de la premura por dar publicidad a las noticias. Así leemos que, el martes santo de 1702, el virrey Conde la Monclova recibió gacetas impresas con noticias de Europa, que el cronista anónimo precisa que, «por hacerse dado a la prensa para remitirse en este correo, se omiten en esta gaceta ${ }^{13}$.

La distribución del Diario se realizó de manera muy eficaz a través del sistema de correos y de chasquis, que permitieron que llegara ampliamente a todos los rincones del virreinato pero, a pesar de ello, desconocemos quién lo leía, cómo estaba compuesto el público lector y el grado de recepción del mismo, si bien estas preguntas sin respuesta no invalidan la importancia enorme de la publicación.

\section{Noticias (graves) del Imperio}

¿Qué pasa, sin embargo, cuando una información llega tarde? Y ¿qué pasa cuando la propia información se demuestra obsoleta, desmentida por algún chisme, rumor o fuente previos, desfasada por consiguiente en cuanto a la actualidad y oportunidad de sus contenidos? ¿Qué ejercicio de reajuste diacrónico implica este enterarse de que uno se entera tarde, como le ocurre a la señora

12 Pedro Guibovich Pérez, «Reseña del Diario de Noticias sobresalientes de Lima y Noticias de Europa...», Lexis, vol. XLI/1 (2017): págs. 243-246, https://doi.org/10.18800/lexis.201701.009.

13 Pedro Guibovich Pérez, «Reseña del Diario de Noticias sobresalientes de Lima..., pág. 246. 
de la película Zama en el asunto revelador de sus perspicaces y adelantadas tacitas o al propio virrey de Monclova, al abrir aquellos cajones oficiales que auguraban nuevas y transmiten y triplican una forma demorada de decepción?

En realidad, la situación parece más problemática —este saber después que la separación con la metrópoli impone en los virreinatos-; sobre todo cuando se está redactando un diario, género de lo actual, instalado en un presente de significado, desde el que se escribe con la simultaneidad como asunto y la connivencia de lo que sucede a la vez.

Por contraste al cultivo de periódicos y noticieros en otras regiones -en Francia, por ejemplo, donde «se les da (...) el nombre de Jornales y en Holanda el de Mercurios» (s.p.)—, en lo que respecta al virreinato del Perú, los diarios vienen prodigándose pero con dolorosas interrupciones, debido a una especie de inexplicable apatía, muy dañina e injustificada, según confiesa la introducción de otra publicación limeña, la Gazeta $^{14}$ aparecida a partir de diciembre de 1743:

En nuestra Corte del Perú y capital del reino la siempre y lustre, y tres veces coronada Ciudad de Lima, se observó constantemente este estilo [de los Diarios], en los tiempos anteriores, el que ha padecido algunos entredichos por una especie de desidia, bastantemente perjudicial al público beneficio y al esplendor y grandeza de una tan circunstanciada Corte $^{15}$.

Para su anónimo redactor, estas publicaciones constituyen una especie de acicate. Son «como los espíritus políticos que animan las repúblicas» y, de hecho, redundan en el cultivo «de la policía de las gentes» ${ }^{16}$.

Quiero insistir, por tanto, en el papel concedido a este «estar al día», a fin de propiciar el correcto funcionamiento de los virreinatos. Al menos así parece

14 Encargada por el virrey, con una distribución muy limitada, la importancia de la Gazeta de Lima radica en su aparición periódica, prácticamente mensual, «which created orderly expectations on the part of the reading public of the time. The oficial periodical (from two to three leaves in length) usually reprinted information from the Madrid press, recounting the most notable social and political events in the life of European courts» (Teodoro Hampe Martínez, «Periodicals, Newspapers, and Pamphlets», en Joanne Pillsbury (ed.), Guide to Documentary Source for Andean Studies 1530-1900, vol. I, Oklahoma, University of Oklahoma Press, 2008, pág. 384)». A la pregunta que Hampe se hace a continuación sobre la capacidad de llamar la atención del público colonial, para José Durand, que estudió su formato y sus variantes en la biblioteca de Hebsburg de la Universidad de Notre Dame donde se conserva, no consideró que esta Gaceta en concreto tuviera mucha demanda (José Durand, ed., Gaceta de Lima, Lima, Corporación Financiera de Desarrollo, 1982 y Gaceta de Lima: De 1793 a junio de 1794, Lima, Oficina de Asuntos Culturales, 1983).

15 Gazeta de Lima. Desde primero de diciembre de 1743. Ha fta 18 de enero de 1744, Lima, En la Imprenta de la Calle de S. Ildephonso, 1744, sin pág.

16 Gazeta de Lima, sin pág. 
sentirse en el Perú del XVIII para el cual la circulación de las «más sobresalientes novedades» contribuye sin duda al gobierno racional de la misma, a su desarrollo y progreso. Y, sin embargo, la situación allí parece enquistarse del lado contrario.

Herodoto definía al historiador como aquel capaz de unir las puntas del intervalo que discurre entre cualquier incidente y su castigo o su reparación: por tanto, se trata de una tarea de dioses por la cual el historiador actúa apuntalando la historia, enlazando sus accidentes y derivando sentido de lo que simplemente trascurre ${ }^{17}$. En cambio, si trazáramos para las colonias ese principio bajtiniano, el cronotopo, que contacta descriptivamente espacio y tiempo, el segundo padecería la relegación característica de las situaciones periféricas que subsisten en la distancia subordinadora del primero.

El mandato de la sucesión consecutiva de los acontecimientos que François Hartog identifica como «régimen de historicidad» se impone férreamente en tanto dispositivo imperial ${ }^{18}$, constructo de sujeción bajo el cual el virreinato subsiste en la constancia de una postergación respecto a hechos cuyo protagonismo, gestión e información compete al corazón del imperio. El conocimiento de lo sucedido en él se distribuye por las colonias en etapas aplazadas, en medidas de separación y morosidad que son operativas, es decir, política y proporcionalmente disuasorias. Porque en la periferia, por definición alejada del centro rector que es el que ordena las secuencias y genera noticias, la temporalidad es la vacía y suspensa de la espera intercalada, del intervalo aparte: el tiempo transcurre fragmentado, disperso, desarticulado, con un ritmo anacrónico de saltos, omisiones.

Frente a la superficie homogénea, coordinada, conclusiva y sistemática de los núcleos metropolitanos, esta anacronía en la que se instala el existir colonial se vuelve entonces su conducta habitual, conducta que además se tematiza en tanto asumido hábito historiográfico. Insistamos en las marcas con que el diario de noticias señala el retraso de las noticias mismas, el modo en que insiste en datar y contar el intervalo que las retiene.

De hecho, en la reflexión filosófica sobre lo temporal que Krzysztof Pomian ${ }^{19}$ reclamaba a la historiografía, merecería un lugar de honor esta capaci-

\footnotetext{
17 «Pour Hérodote, l'histoire était, en son fond, l'intervalle — compte en générations— qui faisait passer d'une injustice à sa vengeance ou à sa reparation», François HaRToG, Régimes d'historicité. Présentisme et expériences du temps, Paris, Éditions du Seuil, 2003, pág. 5.

18 De hecho, para Hartog las relaciones que la sociedad establece con su tiempo no son negociables y el orden temporal bajo el que se rige es el de la sucesión y el mandato. El régimen de historicidad tiene un carácter de obligación y rigidez sobre los individuos que lo conforman con sus vidas individuales.

19 Krzysztof Pomian, L'ordre du temps, Paris, Gallimard, 1984, págs. 5-7.
} 
dad del diario colonial para evidenciar y cronificar — esto es, hacer crónicade las indisposiciones cronológicas que lo habitan, de las crisis, fallas, rupturas, desacuerdos en la elocución abrupta y estancada de sus hechos.

Por tanto, este régimen de historicidad colonial, anacrónica e intercalada, no redunda solo en desventura temporal, es ante todo una oportunidad política de reconstruir el proceso del poder con su organicismo y secuencialidad.

Para verlo con un ejemplo de la Gazeta, antes mencionada, que arranca de 1745, fecha en que comienza a publicarse: a pesar de la determinación de ese inicio, la publicación es incapaz de renunciar a ciertos acontecimientos previos, especialmente jugosos, y, en el tipo de analepsis que el lenguaje cinematográfico popular ha querido llamar precuela, decide hacerse eco de modo sucinto de lo ocurrido el año anterior.

Entre otras cosas, relata la denuncia de un robo de joyas eclesiásticas y la eficaz captura del ladrón, un tal Juan de Valladolid que tiene por hábito no resistirse a sustraer cualquier riqueza que adorne los altares peruanos. Las joyas se devuelven y el ladrón es juzgado y castigado, lo que le permite al gacetillero retrotraerse todavía antes, a la noticia suministrada por un diario de Madrid de 1740, entonces en circulación en Lima, de una sustracción similar en la iglesia romana de Santa Inés, similar salvo por el detalle de que en este caso no se pudo recuperar el alijo ni condenar al delincuente.

El peculiar baile de cifras del episodio comprime, reorganiza, altera y conecta el transcurso histórico en una narrativa tan poderosa como reconstructiva: la gaceta de 1745 da noticia de un suceso de 1744, relatando a continuación algo sucedido en Roma mucho antes y conocido en ese momento en Lima gracias a un noticiero madrileño de 1740.

Es ahora Benedict Anderson el que nos advierte que el tiempo de la colonia se organiza de acuerdo con la modalidad narrativa de la trama, con la orientación de la intriga novelesca en lugar de la secuencialidad historiográfica, orientación dotada por supuesto de consecuencias políticas ${ }^{20}$. Porque con el relato castigado del robo se trata de demostrar la perfecta maquinaria de una periferia que arregla el desorden cronológico precisamente dentro de la superficie ordenancista de una sincronía punitiva, tejiendo suturas y cierres en casos que

20 En realidad Anderson habla de esta temporalidad narrativa de las comunidades imaginadas, una vez ha terminado la perfecta historia de las dinastías monárquicas como el encaje del relato, la historia y la prensa periódica para la promoción de un nuevo sentido nacional. Es Joanne Rappaport la que además insiste en el modo en que la verdad legal se transforma en verdad histórica para el tiempo colonial. Benedict ANDERson, Reflexiones sobre el origen y la difusión del nacionalismo, México, Fondo de Cultura Económica, 2000. Joanne Rappaport y Tom Cummings, Beyond the Lettered City: Indigenous Literacies in the Andes, Durham and London, Duke University Press, 2012. 
el imperio mantendría, por el contrario, en la irresolución de su insignificancia relativa.

\section{El rey pelícano}

Así pues, diríamos que el régimen de historicidad de los virreinatos trabaja con todos los recursos posibles en la legitimación de un relato anacrónico y coopera, por tanto, con el imperio en la reordenación interesada de sus desajustes.

Sin embargo, cuando hablamos aquí de anacronía como marca colonial, no nos referimos al error epistémico o metodológico del historiador —el fallo de interpretar y cristalizar con tentaciones presentistas situaciones del pasado que le son completamente ajenas—: hablar, por ejemplo, de feminismo en Sor Juana o de agnosticismo en Rabelais, el tipo de lapsus hermenéutico que condena Lucien Febvre para el ejercicio de la historia ${ }^{21}$. Por anacronía no entendemos dicho fallo interpretativo, cometido contra cronos, contra la ley temporal de la sucesión; sino, a la manera de Jacques Rancière, al colapso y la superposición de la leyenda y la cronología.

Para Rancière, que acude a Virgilio y al episodio de Dido y Eneas según el cual la fundación de Cartago se coloca de modo imposible antes de la de Roma, la anacronía no concierne solo al ejercicio de remontar equivocadamente un hecho antes que otro. La anacronía opera cuando las fechas se dirigen épicamente hacia una necesidad sin fechas y sirven entonces para reivindicar los derechos de la ficción en la construcción ideológica y mítica de la historia, poniendo entonces en contacto y coaligando, suturando el intervalo con dinámicas distintas de la verdad ${ }^{22}$.

En el caso de la desfasada noticia de la muerte del rey Carlos, resulta curioso el modo en que la propia metrópoli la explica e, incluso, cancela la tardanza mediante ese ejercicio de anacronía, por el cual es posible y conveniente

${ }^{21}$ Lucien Febvre, Le problème de l'incroyance au XVIe siècle. La religión de Rabelais, Paris, Albin Michel, 1968, pág. 15.

22 «To break down the terms of the problem. Anachronism, let us say, does not concern the simple turning back (la remontée) from one date toward another. It concerns moving on from (la remontée) this time of dates toward that which is not the time of dates. This movement indicates two different relations, which I will examine in turn. It is, first of all, a movement toward the time that one cannot date, the time of legends (...) It consisted of an overlapping of legendary times with those of a certified chronology (whatever its exactitude might be). The major example of anachronism mentioned in the classical age is that of which Virgil writes, the loves of Dido and Aeneas. It could be noted that anachronism, the mistake against history par excellence concerns two perfectly fictional characters, lacking any historical reality». Jacques RancièRE, "The Concept of Anachronism and the Historian's Truth», InPrint, $3 / 3$ (2015), https://arrow.tudublin.ie/inp/vol3/iss1/3, (18/12/2020), s.p.) 
pensar en un imperio perfectamente coordinado y cooperante. De hecho, en su Canto fúnebre en la temprana muerte del rey nuestro Señor (que del cielo goza), Juan de Bolea y Alvarado acudirá al recurso lírico de adelantarse a las nuevas oficiales con el apoyo de un sol noticiero que, en su curso hacia el ocaso, notifique velozmente a los indios lo que por vía ordinaria se sabrá prácticamente seis meses después:

\author{
Huyó del Sol el Auriga Luciente, \\ Por no manchar con sombras el Cadáver \\ Y a dar la infausta nueva parte al Indio \\ Dilatando a la Noche las Edades ${ }^{23}$
}

Dilatando o comprimiendo en una noche mítica la totalidad de una temporalidad demorada: es importante esta sustitución de un tiempo humano por el cómputo legendario de una enunciación divina; puesto que a ello se dirige, para Rancière, la capacidad de lo anacrónico en cuanto operación de sumar cronos y mithos en una totalidad sagrada.

De igual forma, en la relación de las exequias por Carlos II que recogiera el jesuita José Rocaberti, con el título Lágrimas amantes de la excelentísima ciudad de Barcelona, relación de las más compendiosas, originales, pesimistas, y que amargamente vaticina los problemas sucesorios derivados de la defunción del rey, ${ }^{24}$ se percibe este ritmo mítico que lo americano imprime a una noticia sentida allí incluso antes de que se produjera, en la conmoción reveladora de sus seísmos y tormentas:

Casi en todos los Estados de su Majestad [a su muerte] han precedido tribulaciones considerables. Acordaos de los prenuncios que nos dieron las Indias, con los estragos del terremoto de Lima Corte del Perú, con las inundaciones que

23 E insiste en esta declaración suavizada del drama: «Enramen jeroglíficos funestos/ Los dinteles de mármoles, y jaspes/ Del templo de la Fama, porque quede/ Suavizado el dolor con lo elegante» (Juan de BoLEA y Alvarado, Canto fúnebre en la temprana muerte del rey nuestro Señor (que del cielo goza) Carlos segundo, En Madrid, por Lucas Antonio de Bedmar y Narvaez... hallárase en su imprenta, en la Calle de los Preziados [ca. 1700], pags. viii y xix)

24 «Qué mayor borrasca para España, que la presente, en que todos naufragamos! Qué noche más funesta, que la que nos asombra con el fatal ocaso de nuestro sol Carlos! Qué tribulación mayor para el español imperio, para el principado de Cataluña, para la excelentísima Barcelona! Oscurezcanse pies los astros catalanes, cáiganse las barceloneses estrellas (...) cáiganse y abísmense en su proprio tormento, en esta obscura noche de penas, en esta tribulación de sentimientos», Ioseph RocABERTi, Lágrimas amantes de la Excelentísima ciudad de Barcelona, con que agradecida a las reales finezas, y beneficios, demuestra su Amor, y su Dolor, en las Magníficas Exequias, que celebró a las amadas y venerables memorias de su difunto rey y señor Don Carlos II (que Dios goza)..., Barcelona, en la Imprenta de Ivan Pablo Marti, por Francisco Barnola, Impresor, 1701, s.f. 
el Mar del Norte hizo en la Isla de la Habana, quedando en entrambas desgracias sepultados muchos o en las ruinas o en las aguas ${ }^{25}$.

Por lo tanto, la noticia de lo que iba a acontecer se habría recibido en la corte peruana bajo las alertas y presentimientos de una naturaleza contrita y trágica. En América no es que las cosas se sepan después, es que se conocen desde muy pronto de un modo celeste y transcendente, con las adivinaciones telúricas de un porvenir ahora adelantado, dentro de una dinámica augural y divina.

En ambos casos, en la noche que comprime tiempo o en el preanuncio ominoso, nos encontramos con dos procedimientos — el poético y el proféticoque, según Rancière, permitirían la reconstrucción ficcional del intervalo, de la espera, y cooperarían de este modo con la visión cristiana de la consumación de los tiempos. Porque la anacronía en que ambos se inscriben no concierne a la horizontalidad del orden secular, sino a la verticalidad de la redención, no a la planicie de la historiográfico sino a la teleología de la política imperial engarzada en un sentido salvífico y mesiánico de la cronología.

De hecho, la muerte de Carlos, con toda la debacle sucesoria y la incertidumbre y peligro de ella derivadas, parece diferirse de manera provisoria al momento en que, ya bajo control, no siembre sospechas que alteren la paz de los criollos. Por eso, a México llega acompañada de la toma de posesión del heredero borbónico, con orden expresa de celebrar su jura en todo el virreinato ${ }^{26}$. Y, para fidelizar a los súbditos transatlánticos, se subraya en Perú el carácter paternal del rey difunto que ha dado su vida por protegerlos.

En todas las villas de la península, los túmulos que se erijan en su homenaje se hacen coronar de la emblemática habitual, encabezada por el fénix que resurge de sus cenizas —Granada, Mallorca, la propia Barcelona ${ }^{27}$ —, en señal

25 Ioseph Rocaberti, Lágrimas amantes de la Excelentísima ciudad de Barcelona..., s.f.

26 Agustín de Mora, El sol eclipsado antes de llegar al zenit: real pira que encendió a la apagada luz del Rey N.S.D. Carlos II el Exmo. Sr, D. Joseph Sarmiento Valadares... en la santa iglesia catedral metropolitana de la ciudad de Mexico..., En México, Por Iuan Ioseph Guillena Carrasco [1701?].

Para la arquitectura efímera que acompaña los festejos relativos a los Reyes, ver Lorene PouncEY, «Túmulos of Colonial Perú», The Art Bulletin, 67-1 (1985), págs. 18-32; Rafael Ramos Sosa, Arte festivo en Lima virreinal (siglos XVI-XVII), Sevilla, Junta de Andalucía, 1992; o bien, entre otros, María Adelaida Allo Manero y Esteban Lorente, «El Estudio de las Exequias Reales de la Monarquía Hispana: Siglos XVI, XVII y XVIII», Artigrama, 19 (2004), págs. 39-94.

27 Bartolomé de CASTRo, Panegírico fúnebre en las Reales Exequias que por nuestro rey... don Carlos II ... rindió... la ciudad de Granada...[S.1.], [s.e.], [1700?]; Melchor Guasp OLIVER, Real pompa funeral, que a las augustas cenizas, y amables memorias del catolico Rey de las Españas, D. Carlos Segundo de Austria, el deseado, consagró .... Nicolás Truyols, y Dameto ... en el Reyno... de Mallorca, a 30 de Noviembre del año 1700, En Mallorca, en la imprenta de Melchior Guasp, 1701; Ioseph RocaberTi, Lágrimas amantes de la Excelentísima ciudad de Barcelona..., s.f. 
de un poder resucitado que se renueva en cada golpe vital; o bien, el águila, blasón heráldico de los Habsburgo, que, cuantiosa y desplegada, se reitera en el panteón de la ciudad de Toledo, en Cuenca o en las exequias madrileñas ${ }^{28}$.

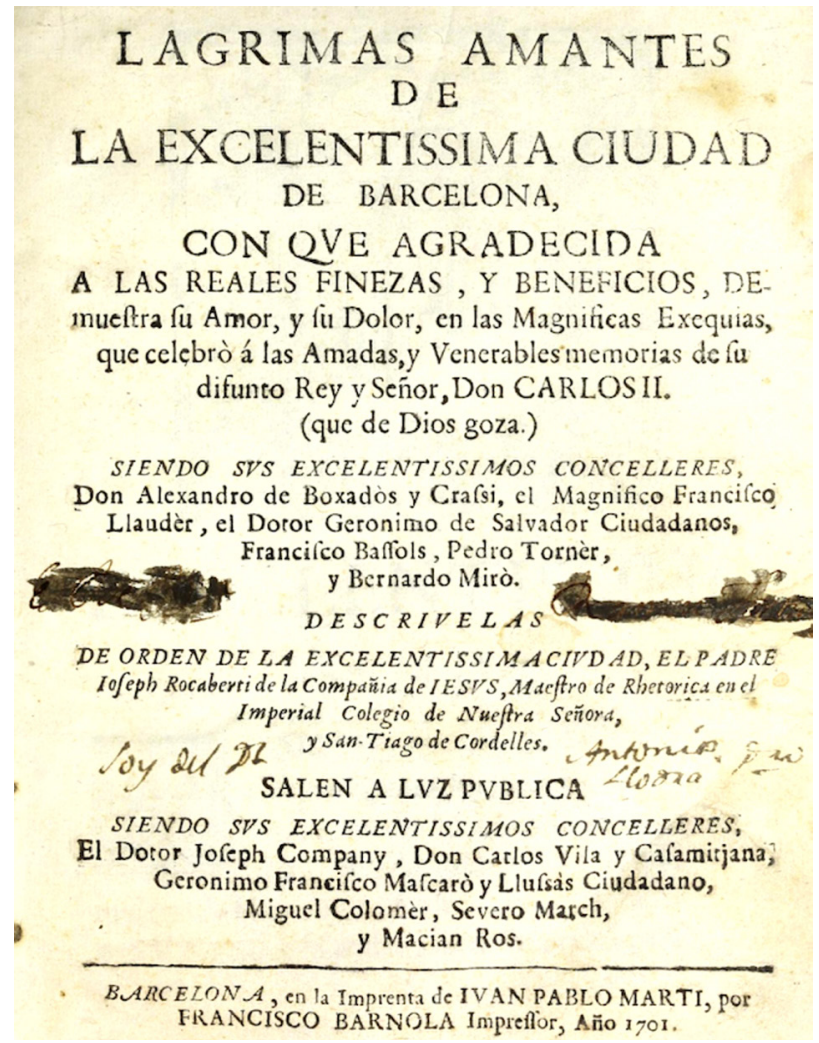

Fig. 3: Joseph Rocaberti, Lágrimas amantes de la Excelentísima ciudad de Barcelona..., Barcelona, en la Imprenta de Ivan Pablo Marti, por Francisco Barnola Impresor, 1701 (Biblioteca Nacional de España)

${ }_{28}$ Exequias reales que a la gloriosa memoria del serenísimo señor Don Carlos Segundo, nuestro señor (que de Dios goza), rey católico de las Españas, celebró en la muy santa Iglesia Primada de la imperial ciudad de Toledo..., En Toledo, Por Agustín de Salas Zazo, Impresor del Rey nuestro Señor, [1701]; Oración fúnebre en las majestuosas lúgubres exequias, que consagró a la inmortal memoria del rey católico de las Españas, nuestro señor don Carlos II, la muy ilustre y antigua ciudad de Cuenca, [Madrid, s.e., 1701]; Bernardino de MADRID, Oración fúnebre en las Reales Exequias, que a nuestro difunto católico monarca D. Carlos II que está en gloria consagró la siempre leal, imperial, coronada villa de Madrid... [Madrid, s.e., 1701]; Antonio de ZAmora, Fúnebre numerosa descripción de las reales exequias que a nuestro difunto católico monarca don Carlos II (que Dios tiene) consagró la siempre real coronada villa de Madrid en el convento real de Santo Domingo de esta corte... el día diez y siete de diciembre deste presente año de 1700... [Madrid]: [s.i.], [1701] 


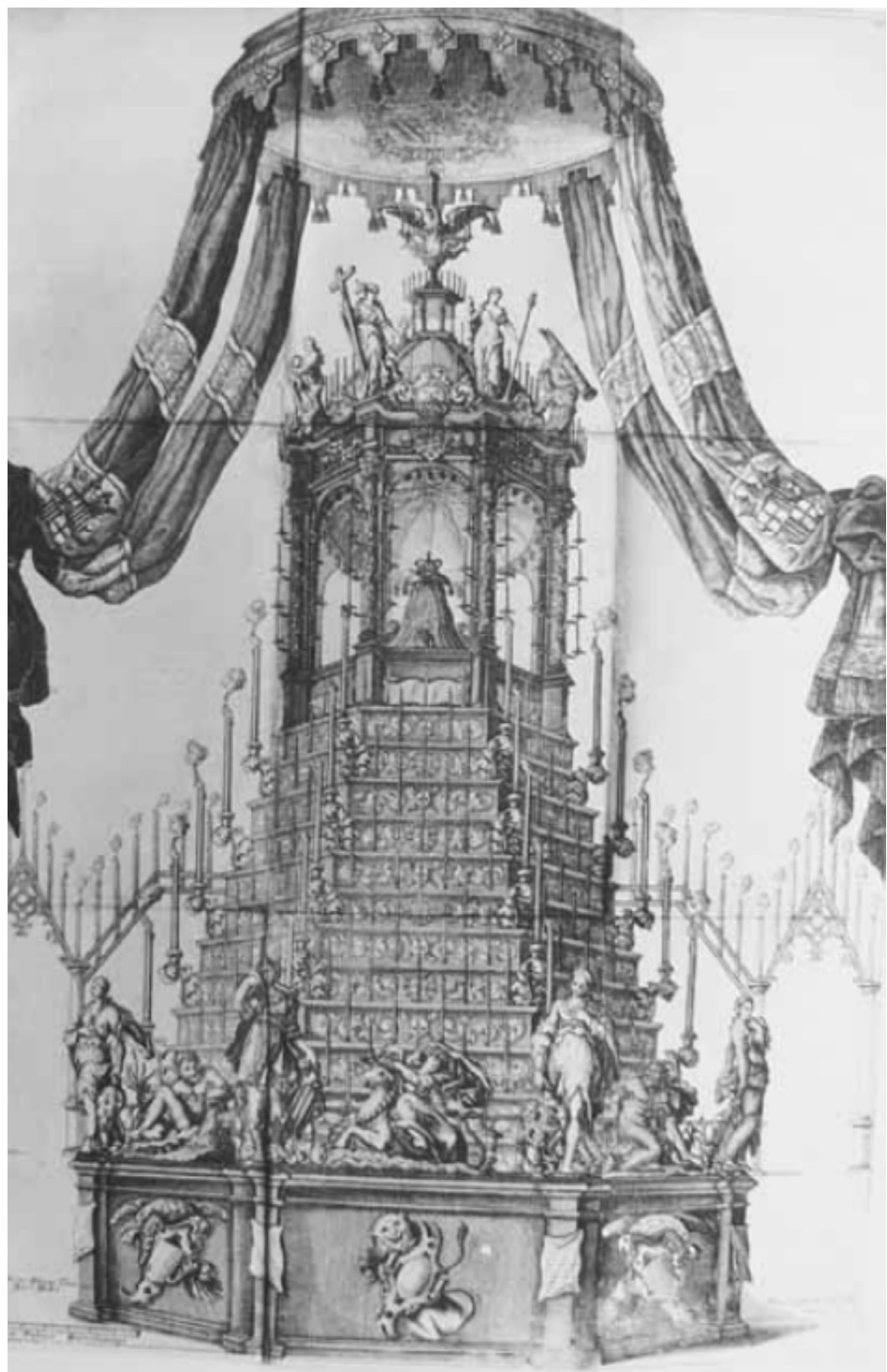

Fig. 4: «Túmulo de Carlos II en la ciudad de Barcelona, 1700». En Joseph RocaberTI. Lágrimas amantes de la Excelentísima ciudad de Barcelona..., Barcelona, en la Imprenta de Ivan Pablo Marti, por Francisco Barnola Impresor, 1701 (Biblioteca Nacional de España) 


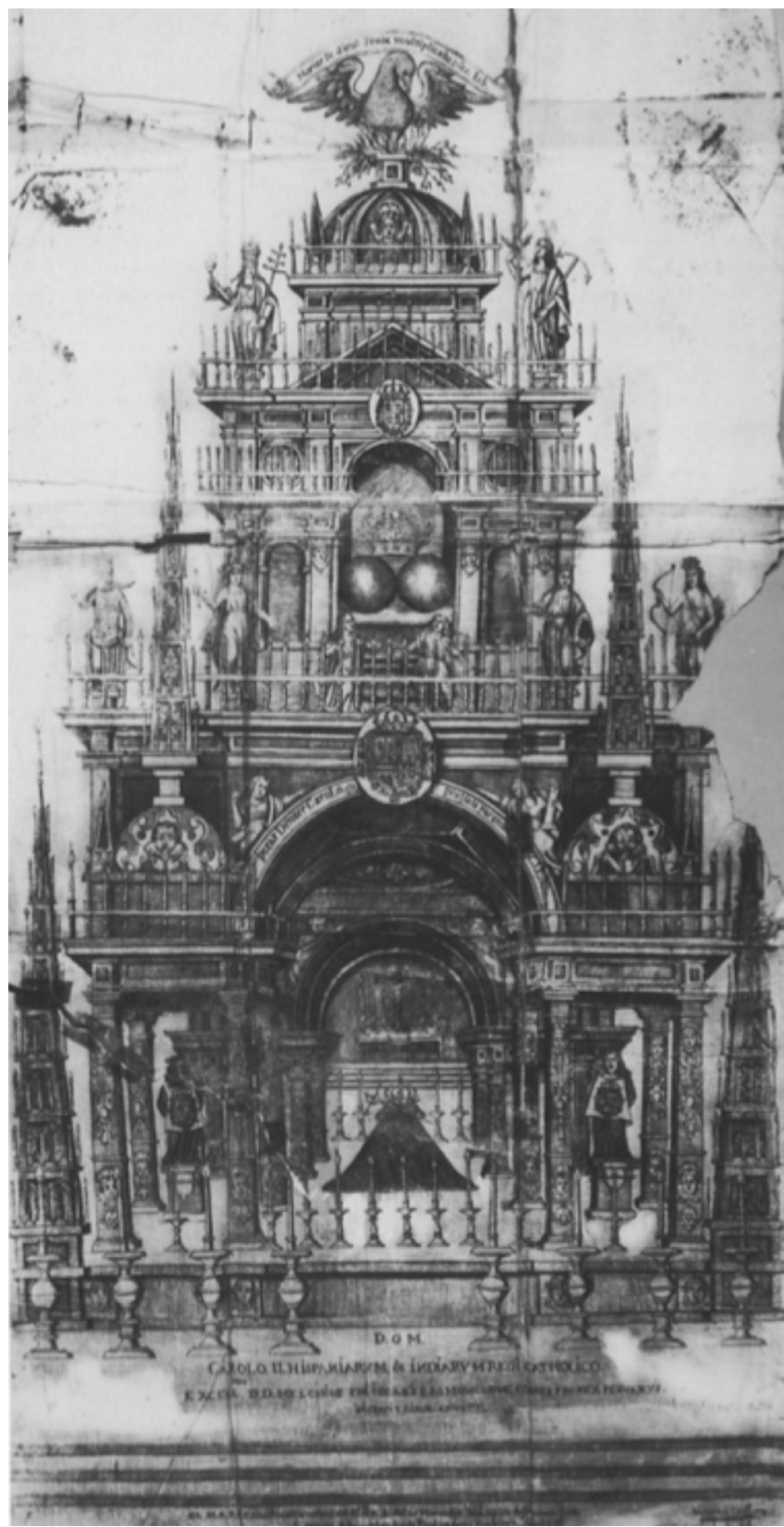

Fig. 5. «Túmulo de Carlos II en Lima», en José de Buendía. Parentación real..., Lima, Joseph de Contreras, 1701. The John Carter Brown Library (Biblioteca Nacional de Perú) 
Pero en Lima la arquitectura efímera que encargará el virrey de Monclova se adorna en una de sus cúpulas con un pelícano abriéndose el pecho y vertiendo su sangre en el buche sediento de sus crías americanas.

Para justificar la simbología, la descripción de los funerales organizados en la ciudad de los Reyes — descripción redactada por José de Buendía como Parentación real al soberano nombre e inmortal memoria del católico rey de las Españas y emperador de las Indias, publicada también por Contreras ${ }^{29}$ - mencionaba la circunstancia de que, diseccionado el cuerpo del rey, se encontró exhausto su corazón, seco de generosa donación a sus súbditos:

Sobre los macizos de las columnas interiores comenzaban a moverse los principales arcos en cada lado en que volaban cuatro bóvedas, dejando en medio un crucero o cuadro cuyo cielo, entre bien labrados artesones, tenía por alma y empresa un pelícano hiriéndose el pecho con el pico por sustentar con su sangre a sus polluelos (...) Símbolo el más proprio del corazón de nuestro Carlos II, a quien en la anatomía de su real cadáver no se le halló gota de sangre, como que toda la hubiese dado a sus vasallos. Que el peso del gobierno es prensa que exprime hasta la última gota de sangre del corazón ${ }^{30}$.

Lejos de marcar esa condición de final de época cuyos peores pensamientos ensombrecen la visión peninsular, en Lima se utiliza la empresa del ave crística que se sacrifica y se entrega. Recordemos que Saavedra Fajardo leía la actuación del pelícano como la propia del príncipe previsor cuya mayor preocupación

29 «La Real sombra que esta urna immensa llora,/ No yace, pasajero: advierte tierno,/ que el vasallo dolor anima eterno/ la mental Majestad, que allí se adora// La piedad del gran Carlos hoy mejora/ No pierde el Español trono paterno,/ Pues de las almas el Imperio interno/ Nueva le jura fé más vividora.// Pasó a númen, pues el que sin ejemplo/ Le hizo reinar, eternizarle puede:/ Le copió imagen, y le guarda Templo// Y porque no sin prole inmortal quede,/ Del casto Lilio, que en su luz contemplo,/ Brote es el celestial, que le sucede», José de Buendía, Parentación real al soberano nombre e inmortal memoria del Católico Rey de las Españas y Emperador de las Indias el serenísimo señor don Carlos II: Fúnebre solemnidad y suntuoso mausoleo que en sus reales exequias en la Iglesia Metropolitana de Lima consagró a sus piadosos manes, el Excmo. Don Melchor Portocarrero Lasso de la Vega, conde de la Monclova..., En Lima, Por Joseph de Contreras, 1701, sin pág. El libro incluía además un soneto del propio impresor.

30 José de Buendía, Parentación real al soberano nombre e inmortal memoria del Católico Rey de las Españas ..., f. 44 v.

De manera más detallada se ofrece en la Gazeta general del 6 de noviembre de 1701, impresa en Madrid para contar tanto la muerte y el entierro de Carlos II como el nombramiento de su sucesor: «El martes a las veinte y cuatro horas de su fallecimiento, se embalsamó el cuerpo del rey nuestro Señor (que Dios haya) Hallaronse las entrañas, hígado y pulmones estiomenados o cancerados, el corazón seco y consumido, deshechas las fibras, sin que en él ni en todo el cuerpo tuviese una gota de sangre», Relación y gaceta general que refiere la muerte, y entierro de nuestro católico Monarca, Carlos Segundo, que Dios aya, con el nombramiento del sucesor para los reinos y dominios de España, Impreso en Sevilla, por Juan Francisco de Blas, 1700, f.1r. 
es mantener la seguridad de la corona que se prolonga en el tiempo sin tiempo de una eternidad monárquica ${ }^{31}$. Por eso, el grabado que abre la Parentación real repite el que ilustraba el Panegírico de su coronación.

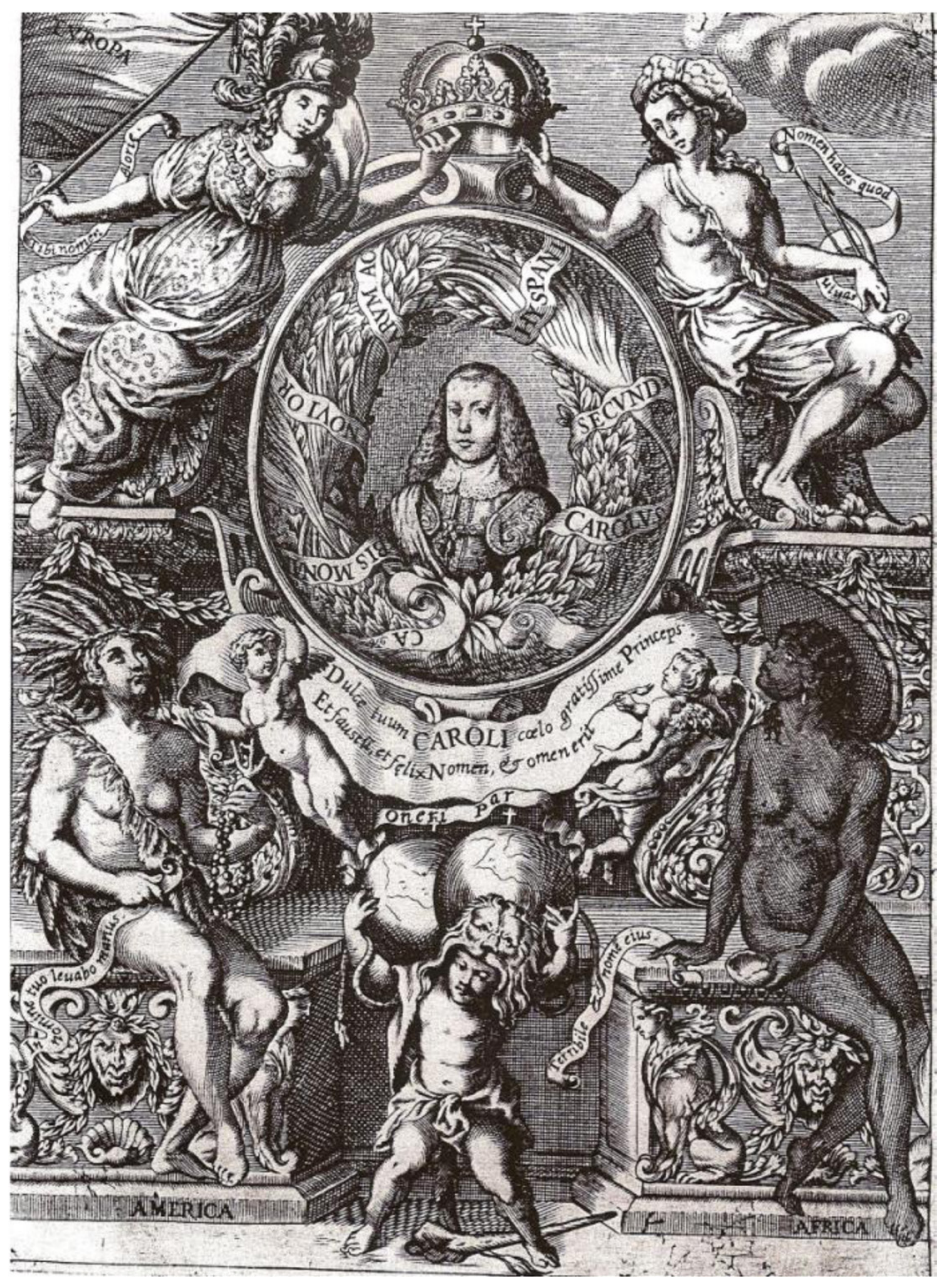

Fig. 6: Jerónimo Basilisco. Las felicidades de España y del mundo cristiano. Panegírico a la proclamación del Rey Carlos II. [Madrid: s.i., 1666] (Biblioteca Nacional de España)

31 Además, Saavedra utilizaba la imagen en su «Empresa 41», referida al emperador Fernando II de Austria, contrastándola con la violencia del águila bicéfala: «No era águila imperial, que con dos severos rostros, desnudas las garras, amenazaba todas partes, sino amoroso pelícano, siempre el pico en las entrañas para dallas como a hijos propios», Diego Sanvedra Fajardo, Empresas políticas, ed. de Sagrario López Pozas, Madrid, Cátedra, 1999, pág. 514. 


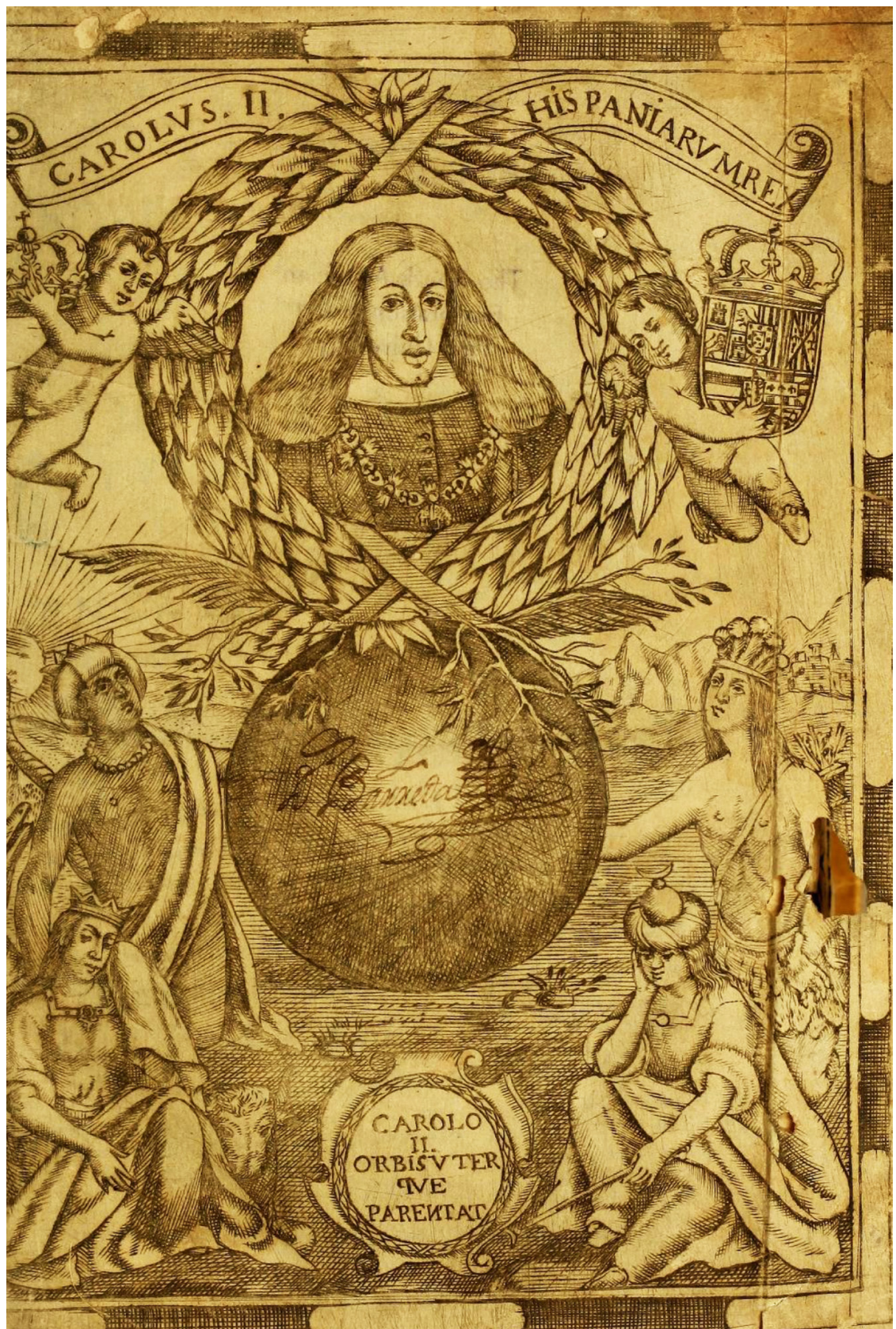

Fig. 7: José de Buendía. Parentación real..., Lima, Joseph de Contreras, 1701 (The John Carter Brown Library) 
Contra lo que los acontecimientos iban a desmentir, lo que se publicita en América es esta imagen de un rey padre que, aun sin descendencia, asegura hasta la última gota de sus venas la suerte de los suyos y la continuidad de la corona. Abundando en la generosidad del difunto y en cuánto hizo por las Indias ${ }^{32}$, se estimulará una memoria anacrónica pero dichosa, que recuerde provisoria e ideológicamente sus acciones, por supuesto también en el Diario de noticias sobresalientes que nos ocupa, al evitarse cualquier alusión a los temores y a la indefensión en que se debate, por el contrario, la corte de Madrid. Son tiempos de contento los que, con la coronación del borbón, en Lima se inauguran, un cómputo que se mide en «días de felicidad pública, que comienza a contarse por los años felices de nuestro rey señor don Felipe $\mathrm{V}$, que prospere el cielo» ${ }^{33}$.

Es verdad que en el Diario se cuenta el desarrollo de la guerra, asimismo con retraso, en una especie de media res que la desrealiza y coloca lejos; mientras que, por contraste, las alusiones a la prosperidad y el contento que la decisión inopinada de Carlos lega a los virreinatos son permanentes, marcando entonces una lectura bienaventurada de la historia. Entre los recursos para confirmar esta transición pacífica y esta época de bonanza, está otra vez la anacronía en su presencia más interesada y ventajosa ${ }^{34}$.

Así, el redactor del Diario de noticias sobresalientes, nada más acabar de contar las reales exequias celebradas en Lima y sin mencionarse aún la toma de posesión de su heredero, se hace eco de la llegada el 28 de junio de unas «reales cédulas», fechadas en Madrid a 11 de enero, con disposiciones que atañen de manera crucial a la seguridad de la costa peruana:

28 [de junio]. Recibió Su Excelencia dos reales cédulas con fechas de Madrid a 11 de enero de este año, mandadas despachar por el Rey nuestro señor, que Dios guarde, y habla en ellas Su Majestad, firmadas de la Reina nuestra señora y señores gobernadores, y refrendadas por el secretario del Real Consejo de las Indias, por mandado del Rey nuestro señor, en que se sirve de mandar avisar a Su Excelencia cómo ingleses y holandeses disponían armada para intentar invadir estas Indias. Y en una de dichas dos cédulas, cita Su Majestad otras que había mandado

32 «Oh cuán dolorido llanto debe ser la memoria de nuestro católico Carlos en estos Reinos, no solo en las personas de primera jerarquía, sino aún de todas esferas; pues deben a su regia liberalidad y beneficencia la amplitud de sus honores y el crecido esplendor que los ilustra en tantos y títulos y togas», José de BuENDía, Parentación real al soberano nombre e inmortal memoria del Católico Rey de las Españas..., págs. 10v-11r.

33 Diario de noticias sobresalientes en Lima..., pág. 117.

34 «...reconociendo Su Excelencia el general alboroto y público regocijo con que ha sido recibida y celebrada en esta ciudad de Lima noticia de tanta felicidad, rebosando en los semblantes de la lealtad española la alegría común por el ingreso a la monarquía de España del rey N.S. don Felipe Quinto», Diario de noticias sobresalientes en Lima..., pág. 113. 
despachar a tres de dicho mes de enero, de que se infiere que vendría en ocasión de aviso formal, que hasta ahora no ha llegado ${ }^{35}$.

Como se precisa en este fragmento, el rey — que debía ser ya Felipe V, pero cuya identidad no se precisa — ha querido alertar al virrey de que «ingleses y holandeses disponían armada para intentar invadir estas Indias», instándole de ese modo a que tome las medidas oportunas. Llamo la atención de que sagazmente en ningún momento se nos dé el nombre del precavido monarca, pero la inmediata inserción del episodio tras la celebración de los funerales y la omisión de la jura del nuevo rey, que aún no se conoce, reorganiza la consecución lógica de los actos en un ritmo tardío pero de intencionalidad manifiesta, engarzando la situación en el proyecto programado de un imperio protegido, guardado y en la iconografía de un difunto vigilante, pelícano insomne, que parece velar, incluso después de muerto, por el destino del mismo.

35 Diario de noticias sobresalientes en Lima..., pág. 104. 